\title{
Effect of Al Addition on the Precipitation Behavior of a Binary Mg-Zn Alloy
}

\author{
Ye-Lim Kim ${ }^{\dagger}$, Hiroyasu Tezuka*, Equo Kobayashi* and Tatsuo Sato* \\ Graduate student, Department of Metallurgy and Ceramics Science, Tokyo Institute of Technology, \\ 2-12-1, O-okayama, Meguro-ku, Tokyo 152-8552, Japan \\ *Department of Metallurgy and Ceramics Science, Tokyo Institute of Technology, 2-12-1, \\ O-okayama, Meguro-ku, Tokyo 152-8552, Japan
}

(Received February 6, 2012 : Accepted February 8, 2012)

\begin{abstract}
The effect of $\mathrm{Al}$ addition on the precipitation behavior of a binary $\mathrm{Mg}-\mathrm{Zn}$ alloy was investigated based on the changes in the morphology, distribution and element concentration of precipitates formed during aging treatment. The as-cast Mg-6.0 mass\%Zn (Mg-6Zn) and Mg-6.0 mass\%Zn-3.0 mass\%Al (Al-added) were homogenized at $613 \mathrm{~K}$ for $48 \mathrm{~h}$ and at $673 \mathrm{~K}$ for $12 \mathrm{~h}$; they were then solid solution treated at $673 \mathrm{~K}$ for $0.5 \mathrm{~h}$ and $1 \mathrm{~h}$, respectively. The Mg- $6 \mathrm{Zn}$ and Al-added alloys were aged at $403 \mathrm{~K}$ and $433 \mathrm{~K}$. The peak hardness of the Al-added alloy was higher than that of the Mg-6Zn alloy at each aging temperature. Rod-like, plate-like, blocky, and lath-like precipitates were observed in the Al-added alloy aged at $433 \mathrm{~K}$ for $230.4 \mathrm{ks}$, although the rod-like and plate-like precipitates were observed in the TEM microstructure of the Mg-6Zn alloy aged at $433 \mathrm{~K}$ for $360 \mathrm{ks}$. Moreover, the precipitates in the Al-added alloy were refined and densely distributed compared with those in the Mg-6Zn alloy. The Cliff-Lorimer plots obtained by the EDS analysis of the rod-like $\beta_{1}^{\prime}$ and plate-like $\beta_{2}^{\prime}$ phases in the Al-added alloy peak aged at $433 \mathrm{~K}$ for $230.4 \mathrm{ks}$ were examined. It was confirmed that the $\beta_{2}$ phases had higher concentration of solute $\mathrm{Al}$ atom than was present in the $\beta_{1}^{\prime}$ phases, indicating that the properties of precipitates can be changed by $\mathrm{Al}$ addition.
\end{abstract}

Key words $\mathrm{Mg}-\mathrm{Zn}-\mathrm{Al}$ alloy, precipitation behavior, transmission electron microscopy (TEM), Cliff-Lorimer plot.

\section{Introduction}

The Mg-Zn alloys have a great potential to improve the strength by various heat treatments and micro-alloying as compared with the Mg-Al alloys which do not generally undergo thermal treatments such as an aging treatment, whereas their strength is industrially achieved through the grain refinement. However, the predominant strengthening $\beta_{1}^{\prime}$ precipitates in the binary $\mathrm{Mg}-\mathrm{Zn}$ alloy are widely reported to exhibit a coarse and inhomogeneous distribution. ${ }^{1-4)}$ It is generally accepted that, for Mg-Zn alloys containing 4-9 mass $\% \mathrm{Zn}$ and aged isothermally at 393$533 \mathrm{~K}$, the strengthening precipitate phases are $\beta_{1}^{\prime}$ and $\beta_{2}^{\prime}$. The metastable $\beta_{1}^{\prime}$ phase forms as rods with its long axis parallel to the $[0001]_{\mathrm{Mg}}$ direction of the $\alpha-\mathrm{Mg}$ matrix, while the metastable $\beta_{2}^{\prime}$ phase forms as plates on $(0001)_{\mathrm{Mg}}$. Historically, it is determined that both $\beta_{1}^{\prime}$ and $\beta_{2}^{\prime}$ phases have a hexagonal structure $(a=0.520 \mathrm{~nm}, c=0.857 \mathrm{~nm})$ that is identical to that of the Laves phase $\mathrm{MgZn}_{2}$. In a newly published paper, it is found that the $\beta_{1}^{\prime}$ phase is mainly formed as $[0001]_{\mathrm{Mg}}$ rods, unlike the $\mathrm{MgZn}_{2}$ structure, with a base-centered monoclinic structure $(a=$

${ }^{\dagger}$ Corresponding author

E-Mail : forever-yl@nate.com (Y. -L. Kim)
$2.596 \mathrm{~nm}, b=1.428 \mathrm{~nm}, c=0.524 \mathrm{~nm}, \gamma=102.5^{\circ}$ ) similar to that of the $\mathrm{Mg}_{4} \mathrm{Zn}_{7}$ phase. ${ }^{1,5-10)}$ In the development of the equilibrium $\beta$ phase during the precipitation heat treatment, several transition phases are formed in a specific sequence as follows: ${ }^{1,11-12)}$

Supersaturated solid solution(SSSS) $\rightarrow$ solute clusters $\rightarrow$ GP zones $\rightarrow \beta_{1}^{\prime}$ (rods and blocky precipitates $\perp\{0001\}_{\mathrm{Mg}}$; $\mathrm{MgZn}_{2}$ or possible $\left.\mathrm{Mg}_{4} \mathrm{Zn}_{7}\right) \rightarrow \beta_{2}^{\prime}$ (coarse plates $/ /\{0001\}_{\mathrm{Mg}}$ and laths $\left.\perp[0001]_{\mathrm{Mg}} ; \mathrm{MgZn}_{2}\right) \rightarrow$ equilibrium $\beta$ phase $(\mathrm{MgZn}$ or $\mathrm{Mg}_{2} \mathrm{Zn}_{3}$ )

The decomposition of the SSSS initially occurs through clustering of solute atoms. Depending on the aging temperature mainly below $373 \mathrm{~K}$ and alloy composition, three types of coherent GP zones may form: GP1 zones as plates on $\{11 \overline{2} 0\}_{\mathrm{Mg}}$, GP2 zones as oblate spheroids on $\{0001\}_{\mathrm{Mg}}$ and GP3 zones as discs on $\{0001\}_{\mathrm{Mg} .}{ }^{12)}$ Recently, spherical GP zones containing a high concentration of $\mathrm{Zn}$ were discovered in the ZM61 alloy aged at $343 \mathrm{~K}$ for $48 \mathrm{~h}$ using TEM and atom probe. GP zones can act as heterogeneous nucleation sites for the transition phases $\beta_{1}^{\prime}$ and $\beta_{2}^{\prime}$ during high temperature aging, resulting in finer microstructure as well as enhanced age hardening response..$^{8-9,13-15)}$

If the effective control of the size and distribution of these precipitates is achieved, the expanded applications of 
magnesium alloys can be expected due to the ultimately improved precipitation hardening. Microalloying is one of the useful methods to produce the finely and uniformily distribted precipites because the additives are expected to affect the formation of small clusters and provide preferential nucleation sites for precipitates. ${ }^{10,12,16)}$ Recently, it has been reported that not only precipitation hardening respons but also microstructure and mechanical properties of Mg-Zn-Mn alloys were improved due to the refined precipitates by the $\mathrm{Al}$ addition., ${ }^{8}$ (17) The Mg-Zn-Al alloys have achieved improved elevated-temperature properties in the as-cast state comparable to those of commercial MgAl-Zn alloys, e.g. AZ91, AM60 and AZ31 alloys. ${ }^{18-19)}$ The $\mathrm{Mg}-\mathrm{Zn}-\mathrm{Al}$ alloys have an advantage to show a sound heat resistance due to the high stability of the $\mathrm{Mg}_{32}(\mathrm{Zn}, \mathrm{Al})_{49}$ phase and the low interfacial energy between the $\mathrm{Mg}_{32}$ $(\mathrm{Zn}, \mathrm{Al})_{49}$ phase and matrix. ${ }^{20)}$ Furthermore, Al containing alloys give good mechanical properties at room temperature due to the solid-solution hardening, excellent tensile properties due to the refined precipiates and good castability.

However, the effect of Al addition and the characteristics of various precipitates in the Mg-Zn-Al alloys are rarely carried out. Therefore, in this study, the effect of $\mathrm{Al}$ addition on enhancing the precipitation hardening was estimated by investigating the aging behaviors and the characteristics of various precipitates in the binary $\mathrm{Mg}-\mathrm{Zn}$ and modified Mg-Zn-Al alloys.

\section{Experimental Procedure}

The as-cast Mg-6.0 mass\%Zn (Mg-6Zn) and Mg-6.0 mass\%Zn-3.0 mass\%Al (Al-added) alloys were prepared by a conventional casting method. The chemical compositions of the $\mathrm{Mg}-6 \mathrm{Zn}$ and $\mathrm{Al}$-added alloys are presented in Table 1. The temperatures for the homogenization and solid-solution treatment were determined using the differential scanning calorimetry (DSC). The DSC was operated ranging from room temperature to $773 \mathrm{~K}$ with $30 \mathrm{mg}$ of $\mathrm{Mg}(99.99 \%)$ as a reference under an argon atmosphere with the heating rate of $10 \mathrm{~K} / \mathrm{min}$. The $\mathrm{Mg}-6 \mathrm{Zn}$ and Aladded alloys were homogenized at $613 \mathrm{~K}$ for $48 \mathrm{~h}$ and at $673 \mathrm{~K}$ for $12 \mathrm{~h}$, respectively. Then the homogenized specimens were solid solution treated at $673 \mathrm{~K}$ for $0.5 \mathrm{~h}$ and $1 \mathrm{~h}$ of the Mg-6Zn and Al-added alloys, respectively. The

Table 1. Chemical compositions of the Mg-6Zn and Al-added alloys.

\begin{tabular}{cccccc}
\hline $\begin{array}{c}\text { Alloys } \\
\text { (mass\%) }\end{array}$ & $\begin{array}{c}\text { Designati } \\
\text { on }\end{array}$ & & $\mathrm{Zn}$ & $\mathrm{Al}$ & $\mathrm{Mg}$ \\
\hline $\mathrm{Mg}-6 \mathrm{Zn}$ & $\mathrm{Mg}-6 \mathrm{Zn}$ & mass\% & 6.39 & - & Bal. \\
& & at.\% & 2.48 & - & \\
Mg-6Zn-3Al & Al-added & mass\% & 6.12 & 2.90 & Bal. \\
& & at.\% & 2.37 & 2.72 & \\
\hline
\end{tabular}

specimens were subsequently aged in oil baths at $403 \mathrm{~K}$ and $433 \mathrm{~K}$. Prior to the experiments, the aged specimens with $\sim 10 \times 10 \times 5 \mathrm{~mm}^{3}$ dimmension were mechanically polished using $120 \sim 4000$ grit emery paper. The precipitation hardening response was examined by the micro Vickers hardness measurement determined from five data out of 7 individual indentations with a load of $200 \mathrm{gf}$ for $15 \mathrm{~s}$. The element distribution and backscattered electron images were obtained using the electrone probe X-ray microanalyzer (EPMA). The existing phase analysis of the alloys were analyzed using the X-ray diffraction analysis (XRD) instrument with the $\mathrm{CuK} \alpha$ radiation at a grazing angle $1^{\circ}$. The XRD patterns were identified by the JCPDS X-ray diffraction databank. The precipitates formed during the aging treatment were observed and characterized using a transmission electron microscope (TEM) equipped with an energy dispersive X-ray spectroscope (EDS). Thin foil specimens for TEM were prepared by punching $3 \mathrm{~mm}$ diameter discs and twin jet electro-polishing using a solution of $8.3 \mathrm{~g} \mathrm{LiCl}, 18.6 \mathrm{~g} \mathrm{Mg}\left(\mathrm{ClO}_{4}\right)_{2}, 833.4 \mathrm{ml}$ methanol, and $166.7 \mathrm{ml}$ 2-butoxy-ethanol at approximately $243 \mathrm{~K}$ with $17 \mathrm{~V}$.

\section{Results}

\subsection{Changes in microstructure}

The DSC measurement was carried out under a controlled heating program in order to understand the characteristic temperatures of the phase transformations evolved during heating. Fig. 1 shows the DSC curves of the ascast $\mathrm{Mg}-6 \mathrm{Zn}$ and $\mathrm{Al}$-added alloys with a heating rate of $10 \mathrm{~K} / \mathrm{min}$. There are endothermic peaks at $614 \mathrm{~K}$ and $630 \mathrm{~K}$ emerging in the curves of the as-cast $\mathrm{Mg}-6 \mathrm{Zn}$ and Al-added alloys, respectively, corresponding to the second phase transformation. It can be inferred that the monotectoid reaction between $\alpha-\mathrm{Mg}$ and $\mathrm{Mg}_{32}(\mathrm{Zn}, \mathrm{Al})_{49}$ phases,

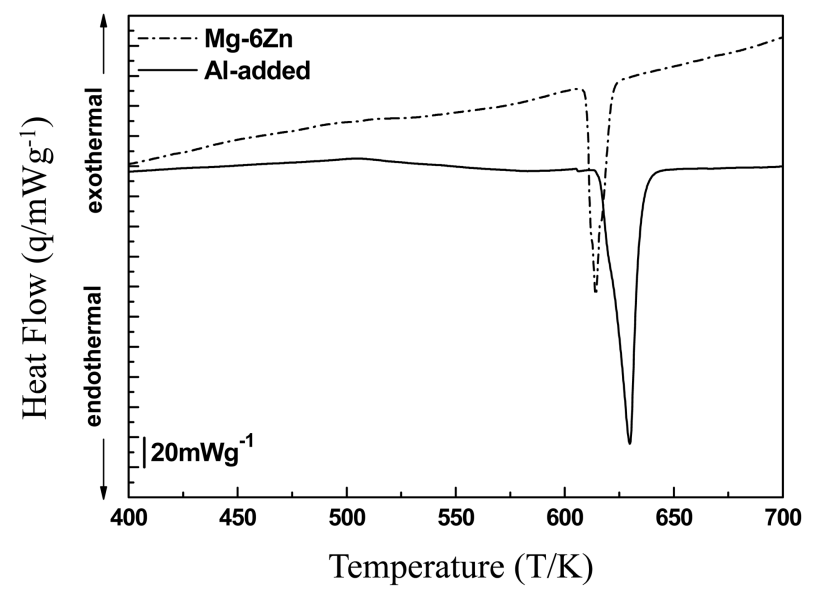

Fig. 1. DSC curve of the as-cast Mg-6Zn and Al-added alloys recorded under a heating program at a controlled speed of $10 \mathrm{~K} / \mathrm{min}$. 


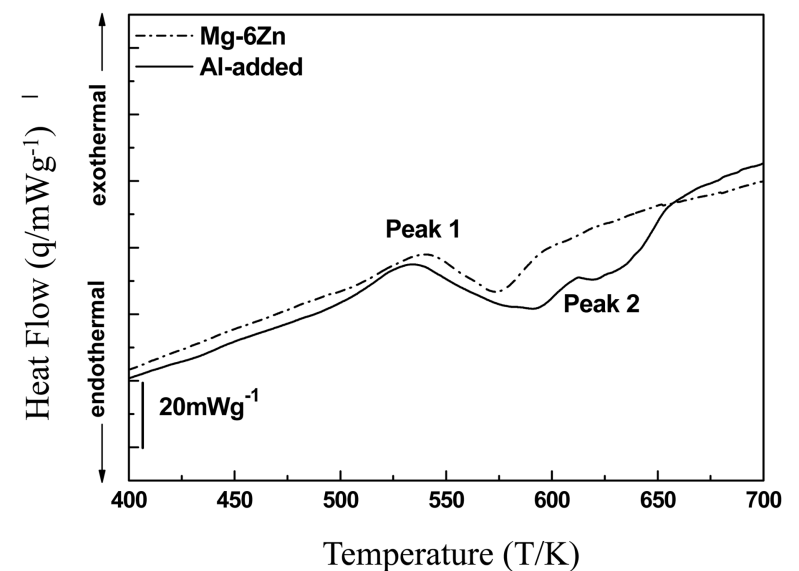

Fig. 2. DSC curve of the solid-solution treated $\mathrm{Mg}-6 \mathrm{Zn}$ and $\mathrm{Al}$-added alloys at $673 \mathrm{~K}$ for $0.5 \mathrm{~h}$ and $1 \mathrm{~h}$, respectively, recorded under a heating program at a controlled speed of $10 \mathrm{~K} / \mathrm{min}$.

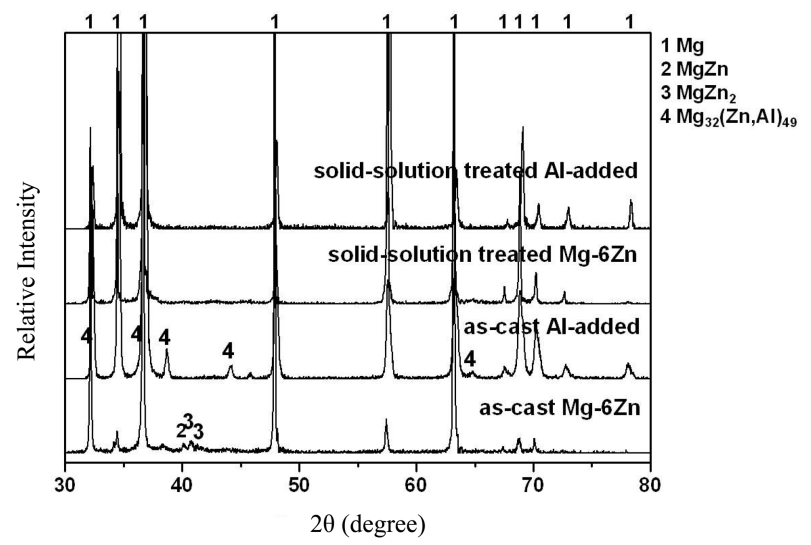

Fig. 3. XRD patterns of the as-cast and solid-solution treated binary $\mathrm{Mg}-6 \mathrm{Zn}$ and ternary Al-added alloys solid-solution treated at $673 \mathrm{~K}$ for $0.5 \mathrm{~h}$ and $1 \mathrm{~h}$, respectively.

which is identified by the XRD analysis in Fig. 3. The endothermic peak at $630 \mathrm{~K}$ of the monotectoid reaction in the Al-added alloy is much higher than that in the Mg$6 \mathrm{Zn}$. The $\mathrm{Al}$ addition affects the formation of thermally more stable phase in the Mg-6Zn alloy. The details are discussed in the explanation parts of Fig. 3 and Fig. 4.

The DSC results of the solid-solution treated $\mathrm{Mg}-6 \mathrm{Zn}$ and Al-added alloys at $673 \mathrm{~K}$ for $0.5 \mathrm{~h}$ and $1 \mathrm{~h}$, respectively, with a heating rate of $10 \mathrm{~K} / \mathrm{min}$ are shown in Fig. 2. The DSC curve for the solid-solution treated Aladded alloy is characterized by two exothermic peaks at $534 \mathrm{~K}$ and $612 \mathrm{~K}$ (tops of the peaks), on the other hand, the DSC curve plotted from the solid-solution treated Mg$6 \mathrm{Zn}$ alloy shows the only exothermic peak at $541 \mathrm{~K}$. The exothermic peaks are attributed to the formations of precipitates. The peak 1 is broaden and shifted from $541 \mathrm{~K}$ to $534 \mathrm{~K}$ by the $\mathrm{Al}$ addition. Furthermore, there is a new peak 2 at $612 \mathrm{~K}$ in the Al-added alloy which is not found in the Mg-6Zn alloy. This may be because of the facts that
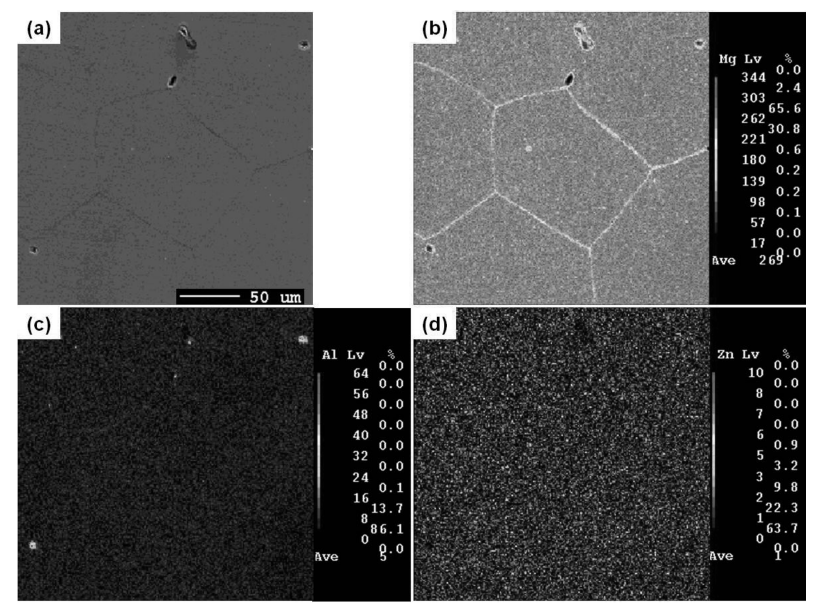

Fig. 4. EPMA results of the solid-solution treated Al-added alloy solid-solution treated at $673 \mathrm{~K}$ for $1 \mathrm{~h}$; (a) BSE image and elemental maps for (b) $\mathrm{Mg}$, (c) $\mathrm{Zn}$ and (d) $\mathrm{Al}$.

either the detected heat representing the peak 2 in the Mg$6 \mathrm{Zn}$ alloy is too small to be detected by the DSC experiments due to the very small volume fraction of the precipitate corresponding to the peak 2 in the $\mathrm{Mg}-6 \mathrm{Zn}$ alloy or the precipitate corresponding to the peak 2 is not formed in the $\mathrm{Mg}-6 \mathrm{Zn}$ alloy. It is noted that the $\mathrm{Al}$ addition caused the different aspect of formation of precipitates compared to that in the Mg-6Zn alloy.

The XRD patterns of the as-cast and solid-solution treated $\mathrm{Mg}-6 \mathrm{Zn}$ and $\mathrm{Al}$-added alloys are shown in Fig. 3. The as-cast $\mathrm{Mg}-6 \mathrm{Zn}$ alloy is consisted of $\alpha-\mathrm{Mg}, \mathrm{MgZn}$ and $\mathrm{MgZn}_{2}$ phases, while the as-cast Al-added alloy is composed of $\alpha-\mathrm{Mg}$ and $\mathrm{Mg}_{32}(\mathrm{Zn}, \mathrm{Al})_{49}$ phases. Almost of the $\mathrm{MgZn}, \mathrm{MgZn}_{2}$ in the $\mathrm{Mg}-6 \mathrm{Zn}$ alloy and $\mathrm{Mg}_{32}(\mathrm{Zn}, \mathrm{Al})_{49}$ phase in the Al-added alloy were completely dissolved after the solid solution treatment. The EPMA result of the solid-solution treated Al-added alloy shown in Fig. 4 supports the XRD result after solid-solution treatment. The elements in the solid-solution treated Al-added alloy were distributed homogeneously in the matrix without any segregation and/or remained intermetallic compounds. It indicates that the supersaturated solid solution in the investigated alloys is successfully obtained and the $\mathrm{Zn}$ and Al mainly act as solute atoms. It is in good agreement with the Mg$\mathrm{Zn}$ binary and Mg-Zn-Al ternary phase diagrams. ${ }^{21-22)}$ However, there is no XRD peak corresponding to the $\mathrm{Mg}_{17} \mathrm{Al}_{12}$ phase which causes poor mechanical properties at higher temperatures above $393 \mathrm{~K}^{20)}$ It is understood that the $\mathrm{Zn}$ addition suppressed the formation of the $\mathrm{Mg}_{17} \mathrm{Al}_{12}$ phase even though 3 mass $\% \mathrm{Al}$ was added. It is confirmed that the $\mathrm{Mg}_{32}(\mathrm{Al}, \mathrm{Zn})_{49}$ phase is produced before the formation of the $\mathrm{Mg}_{17} \mathrm{Al}_{12}$ phase during solidification based on the phase diagram of the Mg-Zn-Al ternary alloy. The $\operatorname{Mg}_{32}(\mathrm{Al}, \mathrm{Zn})_{49}$ phase is formed at $\sim 773 \mathrm{~K}$, while the $\mathrm{Mg}_{17} \mathrm{Al}_{12}$ phase exists at temperatures below $\sim 723 \mathrm{~K}$. 


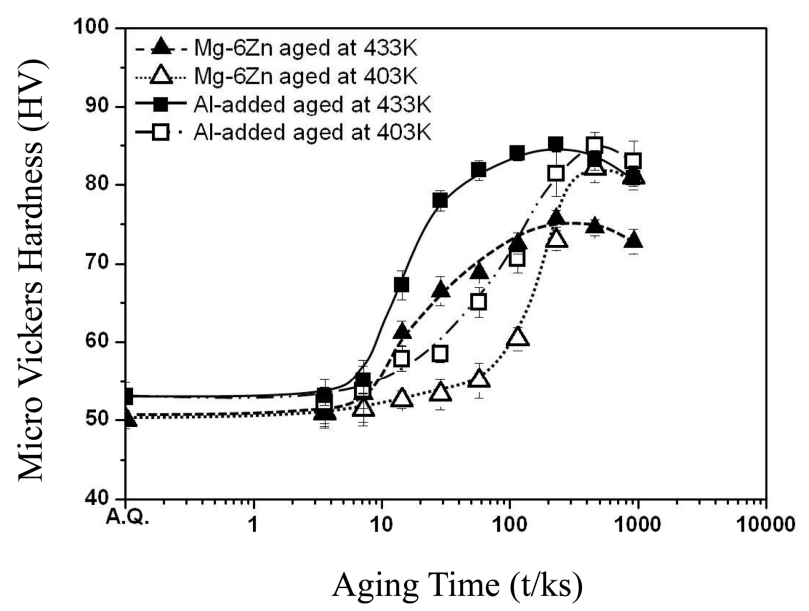

Fig. 5. Micro Vickers hardness changes in the Mg-6Zn and Aladded alloys during aging at $403 \mathrm{~K}$ and $433 \mathrm{~K}$.

\subsection{Changes in hardness during aging treatment}

The age-hardening profiles of the $\mathrm{Mg}-6 \mathrm{Zn}$ and $\mathrm{Al}$-added alloys are shown in Fig. 5. In the initial as-quenched condition, the hardness of the Al-added alloy is higher than that of the Mg-6Zn alloy due to the solid-solution hardening by the $\mathrm{Al}$ addition. A precipitation-hardening behavior is exhibited when the $\mathrm{Mg}-6 \mathrm{Zn}$ and Al-added alloys are exposed to the subsequent aging treatment. Apparently, the precipitation hardening responses of the Al-added alloy were significantly enhanced at $433 \mathrm{~K}$, with the peak hardness of $\sim 85 \mathrm{HV}$ as compared to that of $\sim 76 \mathrm{HV}$ for the $\mathrm{Mg}-6 \mathrm{Zn}$ alloy. However, the difference of peak hardness obtained at $403 \mathrm{~K}$ is smaller as $\sim 82 \mathrm{HV}$ of Mg-6Zn and $\sim 85 \mathrm{HV}$ of Al-added alloys. The Mg-6Zn alloy needs longer incubation time during aging treatment at $403 \mathrm{~K}$ than the Al-added alloy which shows higher increment of hardness after $4 \mathrm{~h}$ of aging time at $403 \mathrm{~K}$. Moreover, the Mg-6Zn and Al-added alloys have almost similar peak aging time as $\sim 128 \mathrm{~h}$ at $403 \mathrm{~K}$ and $\sim 64 \mathrm{~h}$ at $433 \mathrm{~K}$. Note that the addition of $\mathrm{Al}$ enhances the precipitation hardening at $433 \mathrm{~K}$, although the $\mathrm{Al}$ addition is less effective on the improvement of precipitation hardening at $403 \mathrm{~K}$ compared with the Mg-6Zn alloy.

\subsection{TEM microstructures of precipitates}

The TEM microstructures of precipitates in the Mg$6 \mathrm{Zn}$ and $\mathrm{Al}$-added alloys are compared. The TEM bright field images of the $\mathrm{Mg}-6 \mathrm{Zn}$ and Al-added alloys aged at $433 \mathrm{~K}$ for $360 \mathrm{ks}$ and $230.4 \mathrm{ks}$ are shown in Fig. 6 and Fig. 7, respectively. The images were observed along the $<1 \overline{1} 00>_{M g}$ direction. There are two types of precipitates in the Mg-6Zn alloy which can be characterized as a rodlike precipitate parallel to the c-axis of the matrix and a plate-like precipitate with $[10 \overline{1} 0]_{M g}$ direction. As described in the introduction, the precipitates have the certain

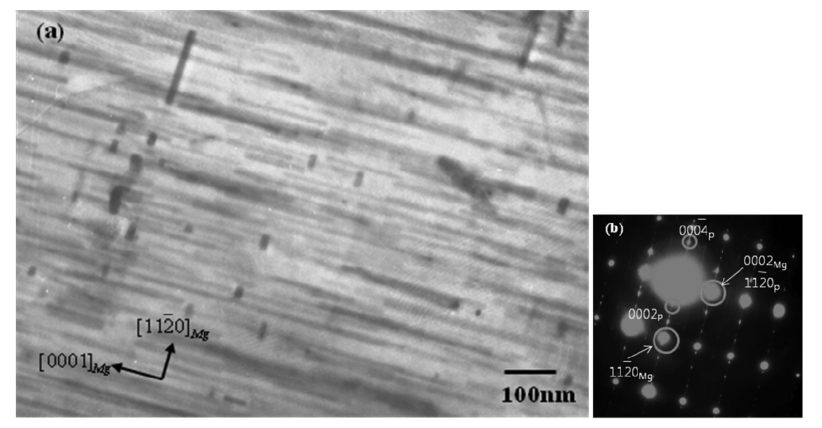

Fig. 6. TEM micrograph of the Mg-6Zn alloy peak aged at $433 \mathrm{~K}$ for $360 \mathrm{ks}$; (a) bright field image and (b) the diffraction pattern of $<1 \overline{1} 00>_{M g}$ beam direction. Electron beam is approximately parallel to $<1 \overline{1} 00>_{M g}$.

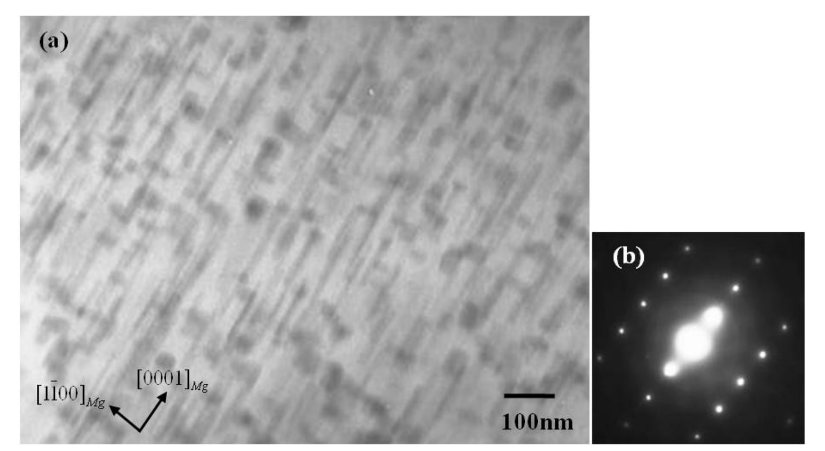

Fig. 7. TEM micrograph of the Al-added alloy peak aged at $433 \mathrm{~K}$ for $230.4 \mathrm{ks}$; (a) bright field image and (b) the diffraction pattern of $<11 \overline{2} 0>_{M g}$ beam direction. Electron beam is approximately parallel to $<11 \overline{2} 0>_{M g}$.

orientation relationships with the $\alpha-\mathrm{Mg}$ matrix..$^{11-12)}$ The details of the orientation relationships are confirmed to be as follows:

- $\beta_{1}^{\prime}$ phase (similar structure to $\mathrm{Mg}_{4} \mathrm{Zn}_{7}$ )

$[0001]_{\beta_{1}^{\prime}} \|[11 \overline{2} 0]_{\alpha}$ and $(11 \overline{2} 0)_{\beta_{1}^{\prime}}^{\prime} \|(0001)_{\alpha}$

- $\beta_{2}^{\prime}$ phase $\left(\mathrm{MgZn}_{2}\right)$

$[1 \overline{2} 0]_{\beta_{2}} \|[10 \overline{1} 0]_{\alpha}$ and $(0001)_{\beta_{2}^{\prime}} \|(0001)_{\alpha}$

Precipitates in the Al-added alloy can be distinguished with four different morphologies, on the other hand only the rod-like and plate-like precipitates observed in the Mg-6Zn alloy. The TEM microstructure of the Al-added alloy consists of not only the rod-like $\beta_{1}^{\prime}$ precipitates and plate-like $\beta_{2}^{\prime}$ precipitates but also a number of blocky $\beta_{1}^{\prime}$ and small volume fraction of lath-shape $\beta_{2}^{\prime}$ precipitates. It is obvious that the Al-added alloy exhibits much higher number density of the blocky and plate-like precipitates compared with the $\mathrm{Mg}-6 \mathrm{Zn}$ alloy. This suggests that $\mathrm{Al}$ affects the nucleation of this morphological and orientational variant of the $\beta_{1}^{\prime}$ and $\beta_{2}^{\prime}$ phases. It is found that the $\mathrm{Al}$ addition to the binary $\mathrm{Mg}-\mathrm{Zn}$ alloy produces 

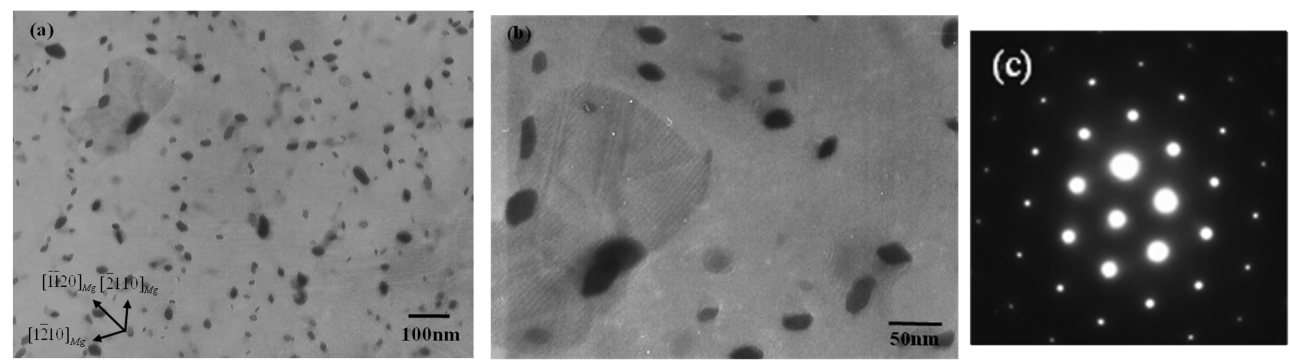

Fig. 8. TEM bright field images of the Mg- $6 \mathrm{Zn}$ alloy peak aged at $433 \mathrm{~K}$ for $360 \mathrm{ks}$ with (a) low magnification and (b), (c) high magnification, and (d) the diffraction pattern of $[0001]_{\mathrm{Mg}}$ beam direction. Electron beam is approximately parallel to $[0001]_{\mathrm{Mg}}$.
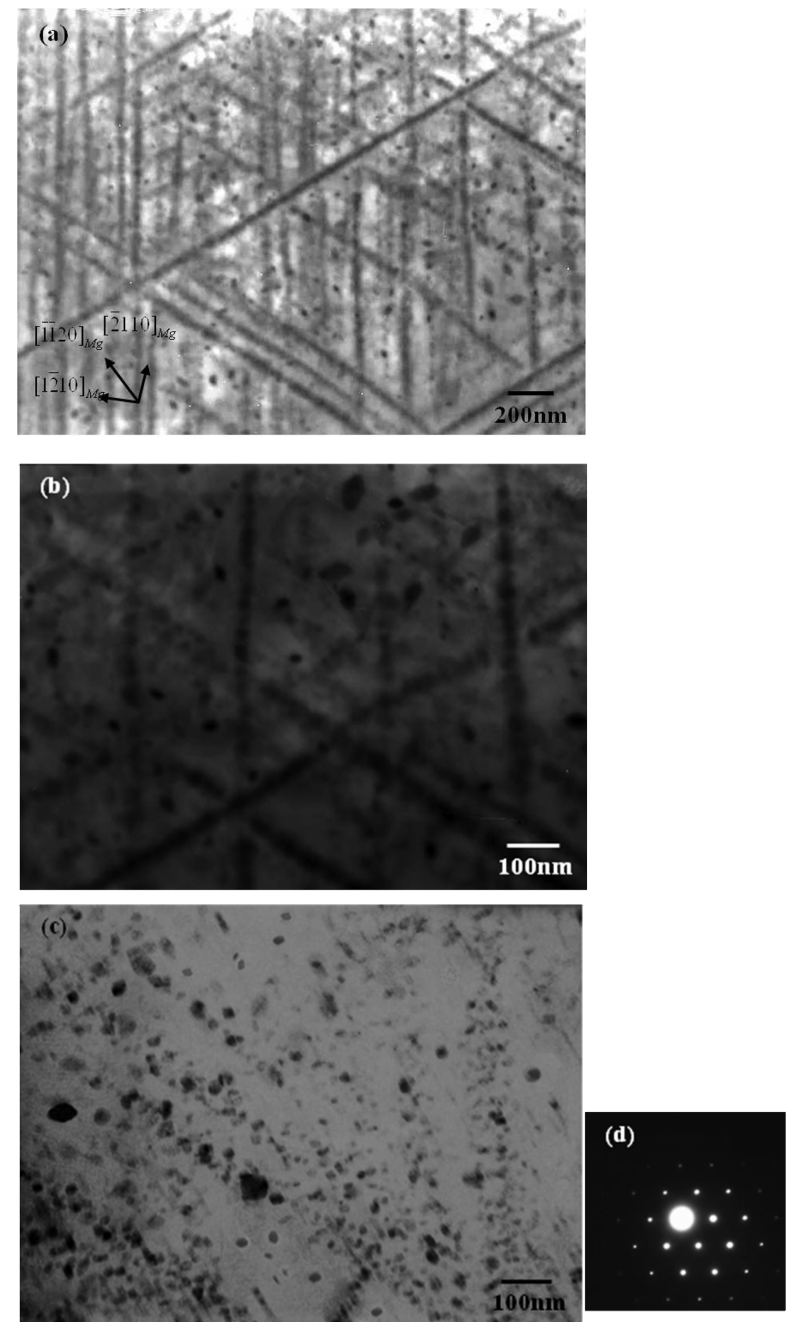

Fig. 9. TEM bright field images of the Al-added alloy peak aged at $433 \mathrm{~K}$ for $230.4 \mathrm{ks}$ with (a) low magnification and (b), (c) high magnification and (d) the diffraction pattern of [0001 $]_{\mathrm{Mg}}$ beam direction. Electron beam is approximately parallel to $[0001]_{\mathrm{Mg}}$.

blocky $\beta_{1}^{\prime}$ and some of lath-shape $\beta_{2}^{\prime}$ precipitates, on the other hand, the microstructures of the aged binary Mg- $\mathrm{Zn}$ alloy consist of two types of precipitates showing the morphologies of rod-like and plate-like shapes. $\left.{ }^{6}{ }^{6} 12\right)$ Fig. 8 and Fig. 9 are the TEM bright field images of the Mg-
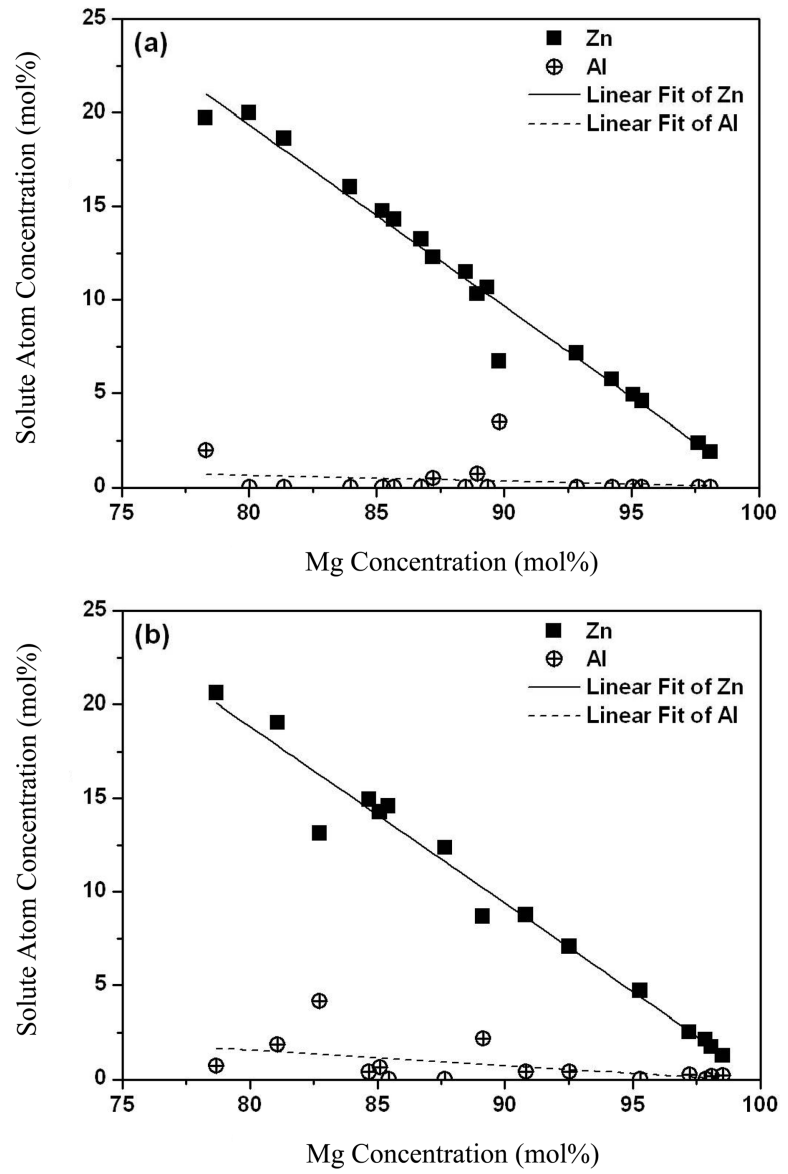

Fig. 10. Cliff-Lorimer plots for the (a) rod-like $\beta_{1}^{\prime}$ and (b) plate-like $\beta_{2}^{\prime}$ phases in the $\mathrm{Al}$-added alloy aged at $433 \mathrm{~K}$ for $230.4 \mathrm{ks}$.

6Zn and Al-added alloys aged at $433 \mathrm{~K}$ for $360 \mathrm{ks}$ and $230.4 \mathrm{ks}$, respectively, observed along the matrix $[0001]_{\mathrm{Mg}}$ direction. The precipitates in the Al-added alloy are more finely and densely distributed compared to those in the $\mathrm{Mg}-6 \mathrm{Zn}$ alloy. In the observation along the $[0001]_{\mathrm{Mg}}$ direction, the rod-like precipitates are aligned along the $<10 \overline{1} 0\rangle_{\mathrm{Mg}}$ as well as the $\{11 \overline{2} 0\}$ prismatic plane direction and the aligned precipitates may contribute to the precipitation hardening which is produced by the plate-like precipitates. 


\section{Discussion}

\subsection{Effect of Al addition on the precipitation hard-} ening of the Mg-Zn alloy

Fig. 10 shows the Cliff-Lorimer plots for the rod-like $\beta_{1}^{\prime}$ and plate-like $\beta_{2}^{\prime}$ phases in the Al-added alloy aged at $433 \mathrm{~K}$ for $230.4 \mathrm{ks}$. The Cliff-Lorimer plots were obtained from the EDS concentration analysis representing solute atoms as a function of the $\mathrm{Mg}$ concentration. The atomic percentages of solute $\mathrm{Zn}$ and $\mathrm{Al}$ atoms were plotted versus concentration of Mg. Then, the least square method was used for calculating the gradient of each straight line of the EDS results as described in Fig. 10. The negative slope of each straight line indicates that the $\mathrm{Zn}$ and $\mathrm{Al}$ atoms are incorporated in the precipitates. The concentration of $\mathrm{Al}$ in the $\beta_{2}^{\prime}$ phase is slightly higher than that in the $\beta_{1}^{\prime}$ phase. It indicates that the $\mathrm{Al}$ addition accelerates the nucleation of the plate-like $\beta_{2}^{\prime}$ precipitates and suppresses their growth during aging. The enrichment of $\mathrm{Al}$ in the precipitates is mainly caused by the strong attractive interaction with $\mathrm{Zn}$. The atomic radiuses of $\mathrm{Al}$ and $\mathrm{Zn}$ are almost similar as 0.182 and $0.153 \mathrm{~nm}$, respectively, which means that $\mathrm{Al}$ and $\mathrm{Zn}$ have almost the similar atomic size; the atomic radius of $\mathrm{Mg}$ is $0.172 \mathrm{~nm}$. It is certain that the $\mathrm{Al}$ addition provides a direct influence on the nucleation and growth of precipitates.

The hardness increases very slightly in the initial stage of aging due to the formation of GP zone. If the precipitate has the same crystal structure and a similar lattice parameter to the $\alpha$-matrix phase, the two phases can form low-energy coherent interfaces on all sides. This situation arises in the early stage of aging. This kind of precipitate is named as a fully coherent precipitate or a GP zone. Even the two crystal structures match more or less perfectly across all interfacial planes, the zone can have any morphology and fully coherent. There are several reports on the formation of the GP zones in Mg$\mathrm{Zn}$ alloys. Mima and Tanaka ${ }^{23-24)}$ examined age-hardening and precipitation sequence in the $\mathrm{Mg}-\mathrm{Zn}$ alloys by electrical resistivity, hardness measurements, and TEM observations, and reported that the microstructures after the aging at room temperature for $270 \mathrm{~h}$ as well as at $383 \mathrm{~K}$ for $100 \mathrm{~h}$ exhibited a mottled structure implying the presence of GP zones. A X-ray diffraction experiment has reported that two types of GP zones are formed as a plate along $\{11 \overline{2} 0\}$ planes and an ellipsoidal shape on the basal planes during aging at temperatures below 333 and $353 \mathrm{~K}$, respectively. ${ }^{25)}$ The present TEM and atom probe results have shown that the GP zones are spherical containing a high concentration of $\mathrm{Zn}$. This could be the first report demonstrating the spherical morphology of the GP zones in the Mg- $\mathrm{Zn}$ alloy system, since there is no article which has ever indicated the clear image of GP zones in Mg-Zn alloys. Also, it seems that the zones do not have an ordered structure. In the early stage of aging of $\mathrm{Mg}-\mathrm{RE}-\mathrm{Zn}-\mathrm{Zr}$ and $\mathrm{Mg}-\mathrm{Ca}-\mathrm{Zn}$ alloys, microstructure analyses using atom probe and high resolution TEM have revealed that the atoms of RE (mainly containing $\mathrm{Ce}$ and $\mathrm{Nd}$ ) and $\mathrm{Ca}$ along with $\mathrm{Zn}$ aggregate on the basal planes, i.e., the formation of monolayer plate-like GP zones. ${ }^{13,16)}$ This is because that the atomic radius of the rare earth elements or $\mathrm{Ca}$ is substantially larger than that of $\mathrm{Mg}$, so the plate-like morphology is energetically favorable. There are no intermetallic compounds between the $\mathrm{Mg}$ and $\mathrm{MgZn}$ at low temperature in a $\mathrm{Mg}-\mathrm{Zn}$ binary phase diagram, and so the existence of a large metastable miscibility gap is expected in the $\alpha-\mathrm{Mg}$ and $\mathrm{MgZn}$ two phase region. Therefore the formation of the Zn-enriched GP zones before the precipitation of the stable $\mathrm{MgZn}$ phase is reasonable. Since the atomic radiuses of $\mathrm{Mg}$ and $\mathrm{Al}$ are more similar than the atomic radiuses of $\mathrm{Mg}$ and $\mathrm{Zn}$, the Al-rich GP zones may be easily formed from the Mg-rich matrix; the atomic radiuses of $\mathrm{Mg}, \mathrm{Zn}$ and $\mathrm{Al}$ are 0.172 , 0.153 and $0.182 \mathrm{~nm}$, respectively. After an incubation time, i.e. midterm stage of aging, the GP zone has a role of nucleation site for the subsequent precipitates. Therefore, higher number density of GP zones in the Al-added alloy than that in the Mg- $6 \mathrm{Zn}$ alloy can produce more precipitates which enhance the hardness during aging.

4.2 Effect of Al addition on the morphology and distribution of the precipitates in the $\mathrm{Mg}-\mathrm{Zn}$ alloy

From the TEM microstructures (Fig. 6 and Fig 7), it is obvious that the Al-added alloy exhibits much higher number density of the plate-like and blocky precipitates compared with the $\mathrm{Mg}-6 \mathrm{Zn}$ alloy. Buha ${ }^{12)}$ reported that the Zn-enrich GP zones are formed on the $\{0001\}_{\mathrm{Mg}}$ planes in the Mg-Zn alloy after aging at $433 \mathrm{~K}$ for 90 min. Moreover, Saito et $\mathrm{al}^{26)}$ found that the planar GP zones in the Mg-Gd-Zn alloy are existed perpendicularly to the c-axis of $\mathrm{Mg}$ matrix and parallel to a-axis of the $\mathrm{Mg}$ matrix after aging at $473 \mathrm{~K}$ for $100 \mathrm{~h}$. Futhermore, the heavier elements, i.e. $\mathrm{Zn}$ and $\mathrm{Gd}$ are enriched into the GP zones while the light element of $\mathrm{Mg}$ is depleted on the locations of the GP zones.

The GP zones in the Mg-Zn-Al alloys investigated in the present study will be formed on the $\{0001\}_{\mathrm{Mg}}$ planes and $\mathrm{Al}$ will be enrich into the GP zones due to the strong interaction energy between $\mathrm{Zn}$ and $\mathrm{Al}$. The lattice misfit between the $\alpha-M g$ matrix and precipitate phases can be changed by the $\mathrm{Al}$ addition. Shin et al. ${ }^{27)}$ discovered that the large solutes, such as $\mathrm{Ca}, \mathrm{K}, \mathrm{Sr}$ and $\mathrm{Ba}$, increase the lattice parameters of $\mathrm{Mg}$ in both a-axis and c-axis significantly, and interestingly $\mathrm{Ba}$ increases a-axis far more than c-axis. From this result, it can be assumed that the Al addition changes more a-axis than c-axis. The misfit across 
the a-axis results large coherency strains parallel to the $(0001)_{\mathrm{Mg}}$, but no coherency strains will exist across the caxis. Therefore, the growth of not only plate-like precipitate but also blocky precipitate in the c-axis of the matrix will be suppressed differently from the rod-like precipitate.

From Fig. 9 observed along the matrix [0001 $]_{\mathrm{Mg}}$ direction, the precipitates in the Al-added alloy are more finely and densely distributed compared with those in the Mg$6 \mathrm{Zn}$ alloy. In observation along the $[0001]_{\mathrm{Mg}}$ direction, the rod-like precipitates are aligned along the $\langle 10 \overline{1} 0\rangle_{M g}$. The aligned precipitates may also contribute to the dispersion hardening. It is found that the precipitates distributed on the prismatic planes of the $\mathrm{Mg}$ matrix were most effective in the dispersion strengthening. ${ }^{13)}$ In general, the stacking fault energy of an alloy decreases with increasing solute elements. It has been reported that the stacking fault energy of pure $\mathrm{Mg}$ is reduced to about one third by the addition of 3 mass $\% ~ A l .{ }^{14)}$ The decrease of the energy can cause the decomposition of dislocations into partial ones with the formation of stacking fault, $1 / 3<11 \overline{2} 0>\rightarrow 1 / 3<10 \overline{1} 0>+1 /$ $3<01 \overline{1} 0>$. It is considered that the precipitation takes place to the $\langle 10 \overline{1} 0\rangle$ directions, and extends to the prismatic planes. It is found that the precipitates distributed on the prismatic planes of the $\mathrm{Mg}$ matrix were most effective in the dispersion strengthening. ${ }^{13)}$ Therefore, refinement and changed morphology and distribution of precipitates could provide improved precipitation strengthening in the $\mathrm{Al}$ containing Mg-Zn alloy.

\section{Conclusion}

In this study, the changes of microstructure and aging behavior of a Mg- 6.0 mass\% $\% \mathrm{Zn}$ alloy by the additions of 3.0 mass\% $\% \mathrm{Al}$ was investigated. The following results were obtained.

1) The as-cast Mg-6Zn alloy is mainly composed of the $\alpha-\mathrm{Mg}, \mathrm{MgZn}$ and $\mathrm{MgZn}_{2}$ phases, while the as-cast Al-added alloy is composed of the $\alpha-M g$ and $M_{32}$ $(\mathrm{Zn}, \mathrm{Al})_{49}$ phases. The $\mathrm{MgZn}, \mathrm{MgZn}_{2}$ and $\mathrm{Mg}_{32}(\mathrm{Zn}, \mathrm{Al})_{49}$ phases are dissolved into the $\alpha-\mathrm{Mg}$ matrix after solidsolution treatment.

2) The peak hardness, obtained at aging temperatures of 403 and $433 \mathrm{~K}$, in the Al-added alloy was higher than that in the Mg-6Zn.

3) The TEM microstructure of the Mg-6Zn alloy aged at $433 \mathrm{~K}$ for $360 \mathrm{ks}$ shows rod-like $\beta_{1}^{\prime}$ and plate-like $\beta_{2}^{\prime}$ precipitates, whereas four types of precipitates are observed in the Al-added alloy at $433 \mathrm{~K}$ for $230.4 \mathrm{ks}$ : rod-like $\beta_{1}^{\prime}$ precipitates parallel to the $[0001]_{\mathrm{Mg}}$ direction, a number of blocky $\beta_{1}^{\prime}$, plate-like $\beta_{2}^{\prime}$ precipitates and small volume fraction of lath-shape $\beta_{2}$ precipitates.

4) The Cliff-Lorimer plots obtained by the EDS analysis of the $\beta_{1}^{\prime}$ and $\beta_{2}^{\prime}$ phases in the Al-added alloy aged at
$433 \mathrm{~K}$ for $230.4 \mathrm{ks}$ indicate that those phases contain solute $\mathrm{Zn}$ and $\mathrm{Al}$ atoms which might affect the nucleation and growth behavior of precipitates.

\section{References}

1. X. Gao and J. F. Nie, Scripta Mater., 56(8), 645 (2007).

2. J. Buha and T. Ohkubo, Metall. Mater. Trans., 39(9), 2259 (2008).

3. M. Shahzad and L. Wagner, J. Alloy. Comp., 486, 103 (2009).

4. H. Y. Kwak and K. H. Lee, Kor. J. Mater. Res., 21(3), 168 (2011) (in Korean).

5. J. S. Chun and J. G. Byrne, J. Mater. Sci., 4(10), 861 (1969).

6. L. Y. Wei, G. L. Dunlop and H. Westengen, Metall. Mater. Trans. A, 26(7), 1705 (1995).

7. X. Gao and J. F. Nie, Scripta Mater., 57(7), 655 (2007).

8. S. S. Park, G. T. Bae, D. H. Kang, I. H. Jung, K. S. Shin and N. J. Kim, Scripta Mater., 57(9), 793 (2007).

9. S. S. Park, Y. S. Oh, D. H. Kang and N. J. Kim, Mater. Sci. Eng., 449-451, 352 (2007).

10. K. Oh-ishi, K. Hono and K. S. Shin, Mater. Sci. Eng., 496(1-2), 425 (2008).

11. J. B. Clark, Acta Mater., 13(12), 1281 (1965)

12. J. Buha, Mater. Sci. Eng., 492(1-2), 11 (2008).

13. D. H. Ping, K. Hono and J. F. Nie, Scripta Mater., 48(8), 1017 (2003).

14. J. Buha, Mater. Sci. Eng., 492(1-2), 293 (2008).

15. J. Buha, J. Alloy. Comp., 472(1-2), 171 (2009).

16. J. C. Oh, T. Ohkubo, T. Mukai and K. Hono, Scripta Mater., 53(6), 675 (2005).

17. S. S. Park, G. T. Bae, D. H. Kang, B. S. You and N. J. Kim, Scripta Mater., 61(2), 223 (2009).

18. J. Zhang, Z. X. Guo, F. Pan, Z. Li and X. Luo, Mater. Sci. Eng., 456(1-2), 43 (2007).

19. Y. Wang, S. Guan, X. Zeng and W. Ding, Mater. Sci. Eng., 416(1-2), 109 (2006).

20. J. Zhang, R. Zuo, Y. Chen, F. Pan and X. Luo, J. Alloy. Comp., 448(1-2), 316 (2008).

21. Alloy Phase Diagrams, ASM Hand book, Vol. 3, p.1100, ed. E. L. Langer, ASM International, Materials Park (1992).

22. Alloy Phase Diagrams, ASM Hand book, Vol. 3, p.1540, ed. E. L. Langer, ASM International, Materials Park (1992).

23. G. Mima and Y. Tanaka, Trans. Jpn. Inst. Met., 12(2), 71 (1971).

24. G. Mima and Y. Tanaka, Trans. Jpn. Inst. Met., 12(2), 76 (1971).

25. T. Takahashi, Y. Kojima and K. Takanishi, J. Jpn. Inst. Light Met., 23(8), 376 (1973).

26. K. Saito, A. Yasuhara and K. Hiraga, J. Alloy. Comp. 509(5), 2031 (2011).

27. D. Shin and C. Wolverton, Acta Mater., 58(2), 531 (2010). 